\title{
Hormone replacement therapy was associated with increased venous thromboembolism and deep venous thrombosis
}

Grady D, Wenger NK, Herrington D, et al, for the Heart and Estrogen/progestin Replacement Study Research Group. Postmenopausal hormone therapy increases risk for venous thromboembolic disease. The heart and estrogen/progestin replacement study. Ann Intern Med 2000 May 2;132:689-96.

QUESTION: In women with coronary artery disease, does hormone replacement therapy (HRT) (oestrogen plus progestin) increase the risk for venous thromboembolism (VTE)?

Source of funding:

Wyeth-Ayerst

Laboratories.

For correspondence: Dr D Grady, University of California, San Francisco, 74 New Montgomery Street, Suite 600, San

Francisco, CA 94105 , USA. Fax +1415386 4044.

A modified version of this abstract also appears in

Evidence-Based

Nursing.
Randomised (unclear allocation concealment*), blinded (patients, investigators, and outcome assessors),* placebo controlled trial with a mean follow up of 4.1 years (Heart and Estrogen/progestin Replacement Study [HERS]).

\section{Setting}

20 US outpatient and community settings.

\section{Patients}

2763 postmenopausal women between 44 and 79 years of age (mean age $67 \mathrm{y}, 89 \%$ white) who had established coronary artery disease and who had not had a hysterectomy. Exclusion criteria were recent coronary events; recent use of hormone therapy; history of VTE, breast cancer, or endometrial cancer; uncontrolled hypertension; diabetes; or other life threatening disease. Follow up was $100 \%$ for mortality and $98 \%$ for other outcomes.

\section{Intervention}

1380 women were allocated to HRT (conjugated equine oestrogen, $0.625 \mathrm{mg} / \mathrm{d}$ plus medroxyprogesterone acetate, $2.5 \mathrm{mg} / \mathrm{d}$ ) and 1383 to placebo. Data on risk factors were collected (fractures, non-fatal myocardial infarction, stroke, congestive heart failure, and transient ischaemic attack).

\section{Main outcome measures}

Documented and suspected VTE events.

\section{Main results}

During follow up, more women in the HRT group had VTE and deep venous thrombosis than women in the placebo group (table) ( $\mathrm{p}=0.003$ and 0.008 , respectively). The groups did not differ for pulmonary embolism $(p=0.08)$ (table), although few pulmonary embolisms occurred (11 in the HRT group $v 4$ in the placebo group). Subgroup analyses showed a trend towardincreased risk for idiopathic VTE (relative hazard 3.1,95\% CI 0.8 to 11.3 ) and increased nonidiopathic VTE (relative hazard 2.5, CI 1.2 to 5.3).

\section{Conclusion}

In older women with coronary artery disease, HRT increased the risk for VTE and deep venous thrombosis.

*See glossary.

Hormone replacement therapy (HRT) v placebo in women with coronary artery diseaset

\begin{tabular}{lllll}
$\begin{array}{l}\text { Outcomes at mean } 4.1 \\
\text { years }\end{array}$ & HRT & Placebo & $\begin{array}{l}\text { Relative hazard } \\
(95 \% \text { Cl) }\end{array}$ & NNH (Cl) \\
\hline Venous thromboembolism & $2.5 \%$ & $0.9 \%$ & $2.7(1.4$ to 5.0$)$ & $256(157$ to 692$)$ \\
\hline Deep venous thrombosis & $1.8 \%$ & $0.7 \%$ & $2.8(1.3$ to 6.0$)$ & $339(198$ to 1150$) \S$ \\
\hline Pulmonary embolism & $0.8 \%$ & $0.3 \%$ & $2.8(0.9$ to 8.7$)$ & Not significant \\
\hline
\end{tabular}

†Abbreviations defined in glossary.

tRelative hazard ratio calculated by using Cox-proportional hazards model with intention to treat analyses. $\S N N H$ for deep venous thrombosis provided by author.

\section{COMMENTARY}

Decisions about HRT seem to get harder every day. Firstly, HERS raised doubts about benefits for heart disease, ${ }^{1}$ and now the report by Grady et al indicates that HRT increases the risk for VTE. Although this finding was not seen in an earlier randomised controlled trial (RCT) in healthy women (only 4 cases of VTE occurred), ${ }^{2}$ comparable risks have been reported in observational studies, ${ }^{3}$ as well as in RCTs of selective oestrogen receptor modifiers like raloxifene. ${ }^{4}$ Thus, the finding is probably real, but is it important? For the average menopausal woman, the risk for VTE is small (smaller than in the HERS participants) and probably less important than other benefits (relief of symptoms and prevention of osteoporosis) or risks (possible increase in breast cancer) of HRT. However, women who have a lower extremity fracture, recent surgery or other admission to hospital, cancer, congestive heart failure, myocardial infarction, or stroke should probably avoid HRT. These factors increase the risk for VTE 2-30-fold, and they accounted for 75\% of all cases of VTE in HERS. In these patients, clinicians should consider bone specific agents for osteoporosis and alternatives to HRT for menopausal symptoms.

An important question is whether topical HRT, which avoids the first pass effects on the liver, carries the same risk. An Italian study, where $80 \%$ of HRT use was with transdermal oestrogen, reported a 2-fold increased risk for VTE but had only 6 exposed cases. ${ }^{5}$

David Atkins, MD, MPH Agency for Healthcare Research and Quality

Rockville, Maryland, USA Jill Miller, MD

Oregon Health Sciences University

Portland, Oregon, USA

1 Hulley S, Grady D, Bush T, et al.JAMA 1998;280:605-13.

2 The Writing Group for the PEPI Trial. JAMA 1995;273:199-208.

3 Perez Gutthann S, Garcia Rodriguez LA, et al. BMJ 1997;314:796-800.

4 Cummings SR, Eckert S, Krueger KA, et al. JAMA 1999;281:2189-97.

5 Varas-Lorenzo C, Garcia-Rodriguez LA, Cattaruzzi C, et al. Am J Epidemiol 1998;147:387-90. 